\title{
The effect of carbon nanotubes on the fracture toughness and fatigue performance of a thermosetting epoxy polymer
}

\author{
T. H. Hsieh • A. J. Kinloch • A. C. Taylor • \\ I. A. Kinloch
}

Received: 14 March 2011 / Accepted: 16 June 2011/Published online: 29 June 2011

(C) Springer Science+Business Media, LLC 2011

\begin{abstract}
Multi-walled carbon nanotubes, with a typical length of $140 \mu \mathrm{m}$ and a diameter of $120 \mathrm{~nm}$, have been used to modify an anhydride-cured epoxy polymer. The modulus, fracture energy and the fatigue performance of the modified polymers have been investigated. Microscopy showed that these long nanotubes were agglomerated, and that increasing the nanotube content increased the severity of the agglomeration. The addition of nanotubes increased the modulus of the epoxy, but the glass transition temperature was unaffected. The measured fracture energy was also increased, from 133 to $223 \mathrm{~J} / \mathrm{m}^{2}$ with the addition of $0.5 \mathrm{wt} \%$ of nanotubes. The addition of the carbon nanotubes also resulted in an increase in the fatigue performance. The threshold strain-energy release-rate, $G_{\mathrm{th}}$, increased from $24 \mathrm{~J} / \mathrm{m}^{2}$ for the unmodified material to $73 \mathrm{~J} / \mathrm{m}^{2}$ for the epoxy with $0.5 \mathrm{wt} \%$ of nanotubes. Electron microscopy of the fracture surfaces showed clear evidence of nanotube debonding and pull-out, plus void growth around the nanotubes, in both the fracture and fatigue tests. The modelling study showed that the modified Halpin-Tsai equation can fit very well with the measured values of the Young's modulus, when the orientation and agglomeration of the nanotubes are considered. The fracture energy of the nanotube-modified epoxies was predicted, by considering the contributions of the toughening mechanisms of nanotube debonding, nanotube pull-out and plastic void growth of the epoxy. This indicated that debonding and pull-out
\end{abstract}

T. H. Hsieh · A. J. Kinloch · A. C. Taylor ( $\square)$

Department of Mechanical Engineering, Imperial College London, South Kensington Campus, London SW7 2AZ, UK

e-mail: a.c.taylor@imperial.ac.uk

I. A. Kinloch

School of Materials, The University of Manchester, Grosvenor Street, Manchester M13 9LP, UK contribute to the toughening effect, but the contribution of void growth is not significant. There was excellent agreement between the predictions and the experimental results.

\section{Introduction}

Thermosetting polymeric materials, such as epoxy polymers, are widely used in composite materials and adhesive applications due to their relatively high modulus, strength and chemical/thermal resistance. However, these polymers are highly crosslinked, and hence are brittle. Therefore, an appropriate modification for improving the toughness of such polymers is required, without degrading their other useful properties. Many ways to toughen thermosets have been discussed, including the use of rubber (e.g. carboxylterminated butadiene-acrylonitrile (CTBN) [1, 2]), thermoplastic [3, 4] and inorganic particles [5, 6].

More recently, the addition of nanoparticles has become a well-established modification to improve the mechanical properties and toughness of thermosetting polymers. Various types of nanoparticles have been used, including silica nanoparticles $[7,8]$, nanoclays $[9,10]$, carbon nanotubes [11-14] or nanofibres [15] and graphene [16]. Blackman et al. [17] also showed that silica nanoparticles could increase the cyclic-fatigue performance of epoxy polymers, in addition to increasing the fracture toughness. Furthermore, this improvement in cyclic-fatigue performance has been found to be carried through to an improved performance of fibre-composite materials based upon such modified polymeric matrices, as has been recently reported by Manjunatha et al. [18].

Nanocomposites modified by carbon nanotubes (CNTs) have been intensively investigated, as CNTs have excellent mechanical properties $[19,20]$ and good interface 
properties when they are used as a reinforcement with polymeric matrices [21]. For example, Yeh et al. [14] have measured a significant increase in the Young's modulus and tensile strength of an epoxy polymer when CNTs were added. Gojny et al. [22] have investigated the fracture toughness of CNT-based polymeric nanocomposites and concluded that using nanotubes several microns long with a high aspect ratio could enhance the fracture toughness. They also showed that the highest value of fracture toughness was obtained when the CNTs were well dispersed in the polymer. Koratkar and co-workers [23-26] have also reported that the addition of $10-20-\mu \mathrm{m}$ long CNTs to an epoxy polymer reduces the rate of crack growth when the material is subjected to cyclic-fatigue loading. However, these authors did not measure the threshold values below which no further crack growth occurs, which is a very important parameter for engineering design studies. The increase in the number of cycles to failure in fatigue by the introduction of CNTs has also been demonstrated for a methylmethacrylate copolymer [27]. In comparison, the addition of milled carbon fibres to a similar polymer gave no improvement in the fatigue life [28].

The main mechanism by which the addition of CNTs increases the observed toughness of the thermosetting epoxy polymers has been identified [22-24, 29] as pull-out of the CNTs from the epoxy polymer when the crack faces open as crack propagation occurs. Further, quantitative modelling of this CNT pull-out mechanism during the fracture of these nanocomposites confirmed that such a mechanism may indeed account for the observed increases in toughness $[29,30]$. However, pull-out requires the CNTs to debond from the matrix, which may also absorb energy. Once debonding has occurred, the constraint on the epoxy is relieved, and so plastic void growth may also occur.

This article discusses the behaviour of multi-walled carbon nanotube (MWCNT)-modified epoxy polymers when subjected to fracture and to cyclic-fatigue loading. This study will use significantly longer MWCNTs than those reported in the literature, and will show the effect of their addition on the threshold fracture energy below which no crack growth occurs. The relative contributions of the debonding, pull-out and void growth mechanisms to the toughness will also be predicted.

\section{Experimental}

\section{Materials}

The aligned MWCNTs, shown in Fig. 1, were produced using a chemical vapour deposition (CVD) process. A liquid solution of ferrocene in toluene $(8.76 \mathrm{wt} \%)$ was injected at a rate of $0.4 \mathrm{ml} / \mathrm{min}$ into a carrier gas preheated at $200{ }^{\circ} \mathrm{C}$ [31]. The carrier gases used in this study were argon and hydrogen, at slightly above atmospheric pressure. The deposited CNTs were grown on silica substrates inside a tubular furnace at a temperature of $760{ }^{\circ} \mathrm{C}$. The asproduced nanotubes are relatively straight and unentangled, with a typical length of $140 \mu \mathrm{m}$ and a diameter of $120 \mathrm{~nm}$. They were scraped off the substrate using a scalpel before being added to the epoxy and sonicated as described below. (It is known that sonication can damage nanotubes, so their length was measured after sonication in the epoxy using scanning electron microscopy after filtering the nanotubes from the epoxy resin. After sonication, the nanotubes were typically $120-\mu \mathrm{m}$ long, indicating that the sonication process did not seriously damage or shorten the nanotubes.)

A diglycidyl ether of bisphenol A (DGEBA) resin, 'LY556' from Huntsman (Duxford, UK), with an epoxy equivalent weight (EEW) of $186 \mathrm{~g} / \mathrm{eq}$ was used. This was cured using a low viscosity anhydride, 'HE 600' from Nanoresins (Geesthacht, Germany) with an anhydride equivalent weight (AEW) of $170 \mathrm{~g} / \mathrm{eq}$. A concentration of only up to $0.5 \mathrm{wt} \%$ of MWCNTs was used, as further increases in the nanotube content resulted in very high viscosities which prevented high-quality cured plates of the materials being produced. The nanotubes were first mixed with the DGEBA using an ultrasonic probe for $30 \mathrm{~min}$ and a mechanical stirrer for $30 \mathrm{~min}$ at $50{ }^{\circ} \mathrm{C}$. The mixture was then blended with the curing agent using the mechanical stirrer for $20 \mathrm{~min}$ at $50{ }^{\circ} \mathrm{C}$, and degassed at the same temperature using a vacuum oven. The resin was poured into a release-coated mould and cured at $100{ }^{\circ} \mathrm{C}$ for $2 \mathrm{~h}$, followed by a post-cure of $10 \mathrm{~h}$ at $150{ }^{\circ} \mathrm{C}$. The mechanical, fracture and fatigue test samples were machined from the resultant 6-mm-thick plates of cured epoxy polymer.

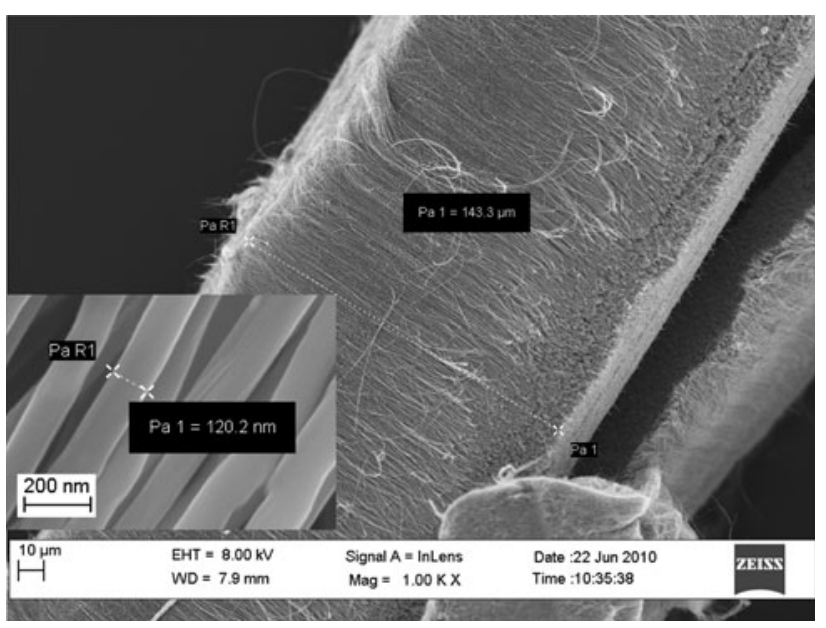

Fig. 1 Scanning electron micrograph of MWCNTs produced by CVD 
Microstructure and thermal studies

Atomic force microscopy (AFM) was undertaken in the tapping mode using a 'MultiMode' scanning probe microscope from Veeco (Plainview, USA) equipped with a 'NanoScope IV controlled J-scanner'. A very smooth surface was first prepared using a 'PowerTome XL' cryoultramicrotome from RMC Products (Tucson, USA).

Transmission optical microscopy (TOM) was performed using slices with a thickness of $100 \mu \mathrm{m}$. The slices were cut from plates of the unmodified epoxy polymer and the nanocomposites, and bonded to a glass microscope slide. The surface was then polished using a rotary plate polisher, starting with a $6 \mu \mathrm{m}$ diamond solution, and decrementing to a $1 \mu \mathrm{m}$ diamond solution. The samples were then carefully cut off the slides and bonded, polished side down, onto a new slide. The samples were then ground down to about $100 \mu \mathrm{m}$ and polished again. The slices were viewed using an 'Axio Scope A1 Materials Microscope' from Carl Zeiss.

Differential scanning calorimetry (DSC) was conducted using a cured sample of about $10 \mathrm{mg}$, according to the ISO Standard 11357-2 [32], employing a 'DSC Q2000' from TA Instruments. The sample was tested using two cycles with a temperature range of $30-180{ }^{\circ} \mathrm{C}$ at a scanning rate of $10{ }^{\circ} \mathrm{C} / \mathrm{min}$. The results of the DSC studies were outputted as curves of heat flow versus temperature, in which the glass transition temperature, $T_{\mathrm{g}}$, was defined as the inflection point in the second heating cycle.

\section{Mechanical properties}

The Young's modulus was measured using uniaxial tensile tests according to ASTM D638 [33] at $1 \mathrm{~mm} / \mathrm{min}$ and room temperature, using a clip-gauge extensometer to measure the displacement of the gauge length. The surfaces of the specimens were polished to remove machining defects.

Single-edge notch-bend (SENB) specimens were machined from the plates, in accordance with ASTM D5045 [34]. A chilled razor blade was tapped into the notched specimens to produce a sharp natural crack. The fracture tests were carried out at a loading rate of $1 \mathrm{~mm} /$ min and at room temperature. The fracture energy was calculated using the energy method, and the fracture toughness was calculated using the fracture load.

The cyclic-fatigue tests were conducted using compact tension specimens [34] in displacement control, with a displacement ratio, $\delta_{\min } / \delta_{\max }$, of 0.5 . Sinusoidal loading was used, with a frequency of $5 \mathrm{~Hz}$. The rate of cyclicfatigue growth per cycle, $\mathrm{d} a / \mathrm{d} N$, was measured [35] as a function of the maximum strain-energy release-rate, $G_{\max }$. The crack length, $a$, was recorded using a crack propagation gauge, 'Krak gage' from Rumul (Neuhausen am
Rheinfall, Switzerland), bonded to the specimen using a very brittle epoxy adhesive. Each test was run until the cyclic-fatigue threshold could be clearly identified, which was after approximately five million cycles. The cyclicfatigue data were analysed using the seven-point polynomial method, according to [35].

Field-emission gun scanning electron microscopy (FEGSEM) of the fracture surfaces was performed using a Carl Zeiss 'Leo 1525 ' with a 'Gemini' column, with a typical accelerating voltage of $5 \mathrm{kV}$. All specimens were coated with an approximately 5-nm thick layer of chromium before imaging.

\section{Results}

The dispersion of the MWCNTs in the epoxy polymer was examined using AFM and TOM. The AFM and TOM images revealed that the nanotubes were agglomerated in the epoxy polymer at all the concentrations employed, see for example Fig. 2. AFM showed that these agglomerates are typically about $5-10 \mu \mathrm{m}$ in diameter. (Note that the nanotubes were measured to be about $120-\mu \mathrm{m}$ long after sonication). Further, as the content of the MWCNTs is increased, the size of the MWCNT agglomerates increases. The FEG-SEM images of the fracture surfaces can also be used to examine the dispersion of the nanotubes, see Fig. $3 \mathrm{~d}$ for example. It is clear that there are many agglomerated CNTs on the fracture surface, a result which agrees with the AFM and TOM observations, and confirms the typical agglomerate size as observed by AFM.

The results of the DSC and quasi-static testing are summarised in Table 1. A glass transition temperature of $147{ }^{\circ} \mathrm{C}$ was measured for the unmodified epoxy, which lies within the range of $145 \pm 2{ }^{\circ} \mathrm{C}$ quoted in the literature for this material $[7,36]$. The addition of nanotubes did not affect the value of $T_{\mathrm{g}}$ within experimental uncertainty, indicating that the polymer's degree of crosslinking is unchanged by the addition of the MWCNTs. A Young's modulus of $2.90 \mathrm{GPa}$ was measured for the unmodified epoxy, and this increased steadily as the nanotube content was increased, as expected [14]. A maximum modulus of $3.26 \mathrm{GPa}$ was measured for the epoxy containing $0.5 \mathrm{wt} \%$ of MWCNTs.

The fracture toughness, $K_{\mathrm{C}}$, and fracture energy, $G_{\mathrm{C}}$, of the epoxy polymers increased steadily as the nanotube content was increased. The measured value of $G_{C}$ for the unmodified epoxy was $133 \mathrm{~J} / \mathrm{m}^{2}$, which shows that this is a brittle polymer, and this value agrees well with that quoted in the literature $[7,36,37]$. The value of $G_{\mathrm{C}}$ was increased to $223 \mathrm{~J} / \mathrm{m}^{2}$ by the addition of $0.5 \mathrm{wt} \%$ of MWCNTs. Examination of the fracture surfaces shows river lines typical of brittle failures, see Fig. 3a, plus evidence which 

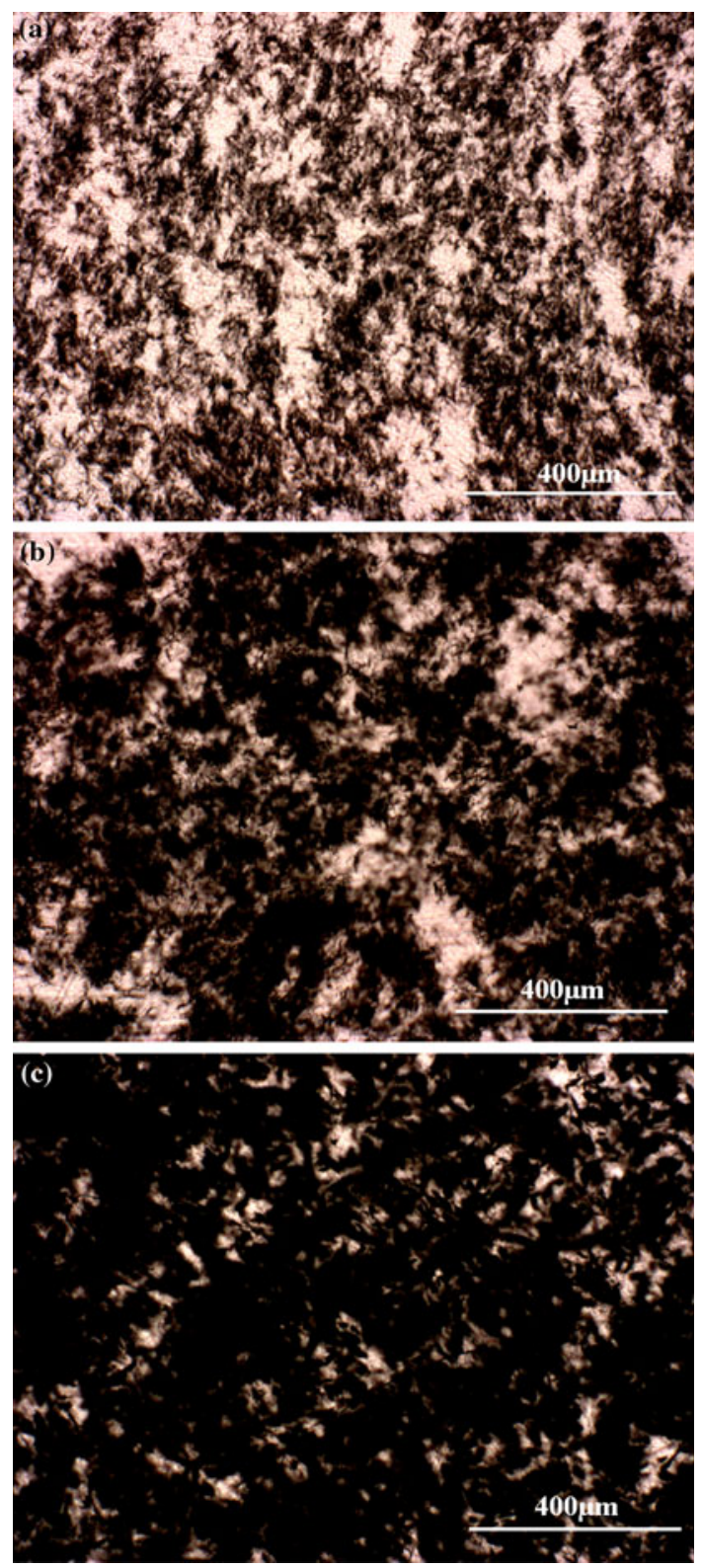

Fig. 2 TOM images of the nanocomposites containing: a $0.1 \mathrm{wt} \%$, b $0.2 \mathrm{wt} \%$ and c $0.5 \mathrm{wt} \%$ MWCNTs

reveals the origin of the toughening mechanisms. Namely, nanotube pull-out and bridging can be clearly observed in Fig. $3 \mathrm{a}$ and $\mathrm{b}$. Here, the mean pulled-out length is $7.8 \mu \mathrm{m}$, with a standard deviation of $\pm 2.8 \mu \mathrm{m}$. Note that the MWCNTs are typically $120-\mu \mathrm{m}$ long after sonication, so the measured average pulled-out length is much shorter than the nanotube length. Thus, the suggested sequence of events is that the nanotubes will first debond from the matrix to allow pull-out. However, as the nanotubes are long and not straight, they rupture rather than pulling-out completely. Therefore, energy will be absorbed by debonding, by friction between the nanotube and the polymer as it is pulled-out and by fracture of the nanotubes. Measurement of the number of pulled-out nanotubes and calculation of the total number of nanotubes from the volume fraction showed that $100 \%$ of the nanotubes exhibited pullout when 0.1 or $0.2 \mathrm{wt} \%$ were used. At the highest volume fraction of $0.5 \mathrm{wt} \%$, then only $62 \%$ of the nanotubes exhibited pull-out.

Voids due to debonding between MWCNTs and the matrix followed by plastic deformation of the epoxy (i.e. plastic void growth) can also be observed, see Fig. 3c. This mechanism has been reported for this epoxy, but modified with silica nanoparticles, by Hsieh et al. [38]. These processes will also absorb energy, and hence increase the measured toughness. However, note that void growth was only observed around $8 \%$ of the nanotubes.

The fatigue performance of the MWCNT-modified composites is shown in Fig. 4, as a plot of the logarithmic rate of crack growth per cycle, $\mathrm{d} a / \mathrm{d} N$, versus the logarithmic maximum applied strain-energy release-rate, $G_{\max }$, in the fatigue cycle. The data follow the expected modified Paris law relationship [39]. In accordance with the fatigue testing standard [35], the value at end of the test (when the crack effectively stops growing) is the maximum applied strain-energy release-rate in the threshold region, $G_{\mathrm{th}}$, as summarised in Table 2. From Fig. 4, it is clear that the addition of the CNTs increased the threshold, from $24 \mathrm{~J} / \mathrm{m}^{2}$ for the unmodified material to $73 \mathrm{~J} / \mathrm{m}^{2}$ for the epoxy polymer containing $0.5 \mathrm{wt} \% \mathrm{CNTs}$. The effectiveness of the nanotubes at increasing the fatigue performance can be seen by considering the ratio of $G_{\mathrm{th}} / G_{\mathrm{C}}$. Typical values for this ratio from the literature, e.g. [40-42], lie in the range of $0.05-0.35$, so the modification with nanotubes is highly effective, as values of $G_{\mathrm{th}} / G_{\mathrm{C}}$ up to 0.33 were measured, see Table 2. Similar increases in the threshold strainenergy release-rate have previously been reported by Blackman et al. [17] using silica nanoparticles. The gradient of the logarithmic rate of crack growth per cycle, $\mathrm{d} a / \mathrm{d} N$, versus the logarithmic maximum applied strainenergy release-rate, $G_{\max }$, in the Paris law region is not significantly affected by the addition of the MWCNTs.

The fracture surfaces of the fatigue specimens were examined using FEG-SEM. The fracture surfaces are shown in Fig. 5, where the images are representative of three different zones viz: the onset of fatigue crack initiation (where $G_{\max }$ is large), fatigue crack propagation and the fatigue threshold (where $G_{\max }=G_{\mathrm{th}}$ ) regions. The crack initiation region was similar in appearance to the fracture surfaces from the fracture tests described above, which also showed river lines. The relatively featureless glassy surface can be seen in the propagation and threshold region. At the high magnification, nanotube pull-out can be observed clearly in the images. In the threshold region, voids can be seen around the nanotubes, as shown in Fig. 6, 

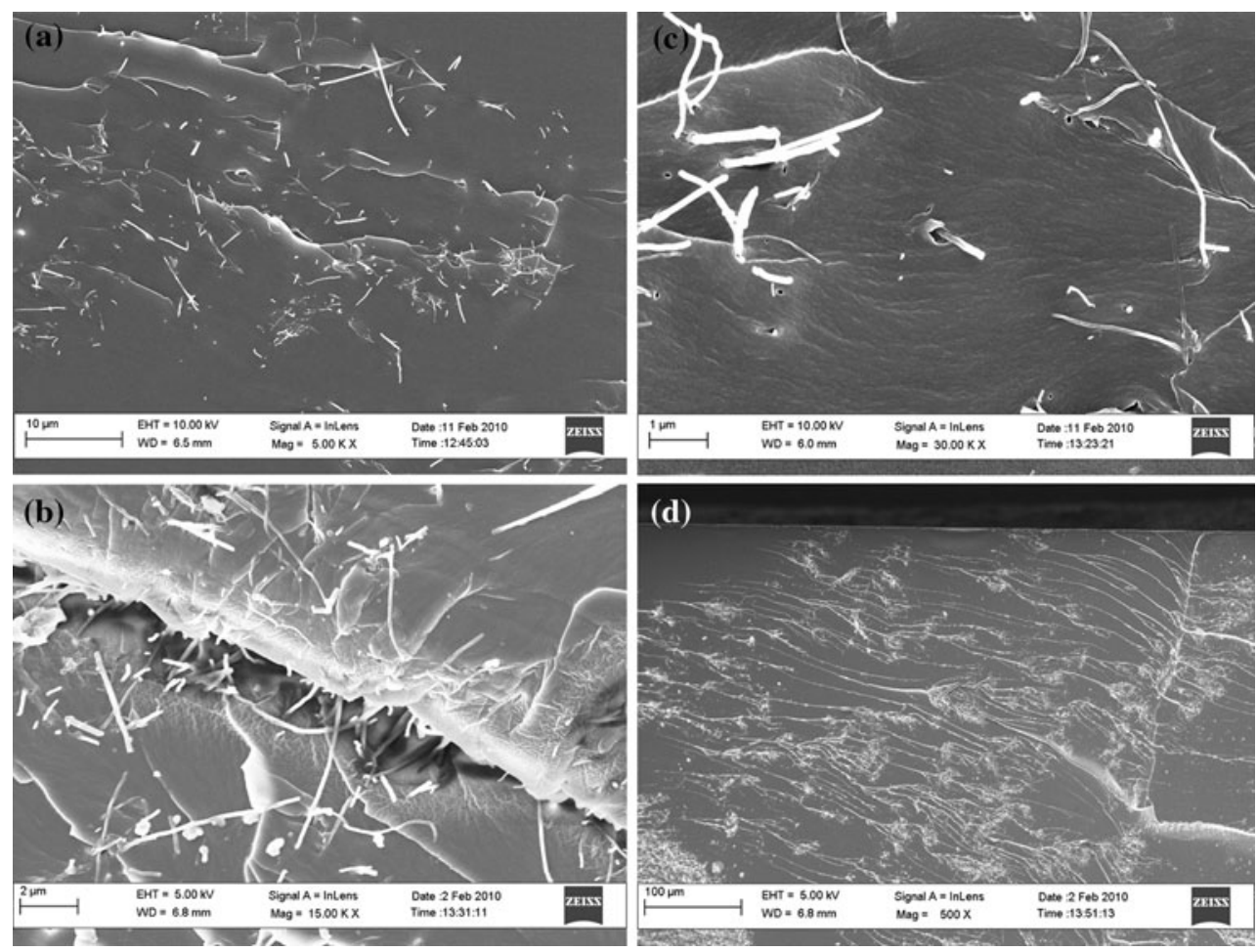

Fig. 3 FEG-SEM image of the nanocomposite containing $0.5 \mathrm{wt} \%$ MWCNT, showing a nanotube pull-out, $\mathbf{b}$ nanotube bridging, $\mathbf{c}$ voids around nanotubes and $\mathbf{d}$ nanotube dispersion. (Crack growth is from right to left)

Table 1 Glass transition temperature, Young's modulus, fracture toughness and fracture energy of the formulations

\begin{tabular}{|c|c|c|c|c|c|c|c|}
\hline \multirow[t]{2}{*}{ Formulation } & \multirow[t]{2}{*}{$T_{\mathrm{g}}\left({ }^{\circ} \mathrm{C}\right)$} & \multicolumn{2}{|c|}{$E(\mathrm{GPa})$} & \multicolumn{2}{|c|}{$K_{\mathrm{C}}\left(\mathrm{MPa} \mathrm{m}{ }^{1 / 2}\right)$} & \multicolumn{2}{|c|}{$G_{\mathrm{C}}\left(\mathrm{J} / \mathrm{m}^{2}\right)$} \\
\hline & & Mean & $\mathrm{SD}$ & Mean & SD & Mean & SD \\
\hline Control & 147 & 2.90 & 0.09 & 0.69 & 0.03 & 133 & 8 \\
\hline $0.1 \mathrm{wt} \%$ & 147 & 3.01 & 0.06 & 0.85 & 0.04 & 162 & 14 \\
\hline $0.2 \mathrm{wt} \%$ & 146 & 3.11 & 0.05 & 0.88 & 0.02 & 188 & 7 \\
\hline $0.5 \mathrm{wt} \%$ & 144 & 3.26 & 0.05 & 0.98 & 0.05 & 223 & 13 \\
\hline
\end{tabular}

due to debonding between CNTs and the matrix followed by plastic deformation of the matrix. By observing the side of the tip of the wedged-open fatigue crack, the SEM images, as shown in Fig. 7, clearly indicate the CNT pullout mechanism. Hence similar mechanisms increase the fatigue performance as were observed to increase the fracture energy in the quasi-static tests.

\section{Modelling studies}

Young's modulus

An analytical model was used to describe the Young's modulus, $E$, of the CNT-modified polymers. The HalpinTsai model [43-45] was designed for unidirectional fibre- reinforced polymers, and the predicted modulus is given by:

$E=\frac{1+\xi \eta \mathrm{V}_{\mathrm{f}}}{1-\eta \mathrm{V}_{\mathrm{f}}} E_{\mathrm{m}}$

in which $V_{\mathrm{f}}$ is the volume fraction of reinforcement, $E_{\mathrm{m}}$ is the Young's modulus of the matrix and $\xi$ is the shape factor, given by:

$\xi=2\left[\frac{l_{\mathrm{f}}}{D_{\mathrm{f}}}\right]$

where $l_{\mathrm{f}}$ is the length of the reinforcement, $D_{\mathrm{f}}$ is the diameter of the reinforcement, and

$\eta=\frac{\left[\frac{E_{\mathrm{f}}}{E_{\mathrm{m}}}\right]-1}{\left[\frac{E_{\mathrm{f}}}{E_{\mathrm{m}}}\right]+\xi}$

where $E_{\mathrm{f}}$ is the Young's modulus of the reinforcement.

Equation 1 was deduced for composites with aligned fibrous reinforcements. However, in this study the orientation of the MWCNTs has a more random distribution. The nanotubes themselves are also not straight. The effect of nanotube waviness on the modulus of nanotube-modified polymers has been analysed by various authors, e.g. [46-48]. However, waviness can be considered to simply locally change the orientation of the nanotubes. Cox [49] considered the effect of orientation on the stiffness of 


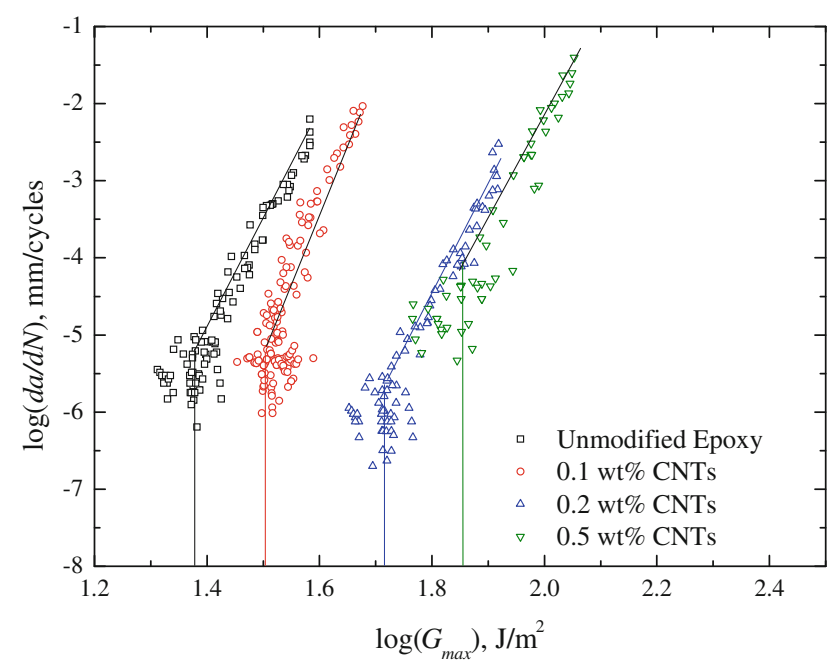

Fig. 4 Rate of crack growth versus maximum applied strain-energy release-rate in the fatigue cycle for unmodified epoxy and nanocomposites

Table 2 Fracture energy, fatigue threshold strain-energy release-rate, $G_{\mathrm{th}}$, and $G_{\mathrm{th}} / G_{\mathrm{C}}$ ratio for the formulations

\begin{tabular}{lllrllll}
\hline Formulation & $V_{\mathrm{f}}(\%)$ & \multicolumn{2}{l}{$G_{\mathrm{C}}\left(\mathrm{J} / \mathrm{m}^{2}\right)$} & & \multicolumn{2}{l}{$G_{\mathrm{th}}\left(\mathrm{J} / \mathrm{m}^{2}\right)$} & \multirow{2}{*}{$G_{\mathrm{th}} / G_{\mathrm{C}}$} \\
& & Mean & $\mathrm{SD}$ & & Mean & $\mathrm{SD}$ & \\
\hline Control & 0 & 133 & 8 & 24 & 8 & 0.18 \\
$0.1 \mathrm{wt} \%$ & 0.063 & 162 & 14 & 32 & 4 & 0.20 \\
$0.2 \mathrm{wt} \%$ & 0.125 & 188 & 7 & 52 & 7 & 0.28 \\
$0.5 \mathrm{wt} \%$ & 0.313 & 223 & 13 & 73 & 2 & 0.33 \\
\hline
\end{tabular}

composites and introduced an orientation factor, $\alpha$, into the Halpin-Tsai model by modifying the value of $\eta$ :

$\eta=\frac{\left[\frac{\alpha E_{\mathrm{f}}}{E_{\mathrm{m}}}\right]-1}{\left[\frac{\alpha E_{\mathrm{f}}}{E_{\mathrm{m}}}\right]+\xi}$.

The orientation factor presents the relationship between the thickness of the specimen and the length of the reinforcement. When the length of the reinforcement is much smaller than the thickness of the testing specimen, $\alpha=1 / 6$ is used [49]. However, when the length of the reinforcement is much longer than the thickness of the test specimen, $\alpha=1 / 3$ is used. The length of the nanotubes used in this study is around $120 \mu \mathrm{m}$, which is much smaller than the thickness of the tensile testing specimens (of $6 \mathrm{~mm}$ ); therefore, the orientation factor $\alpha=1 / 6$ will be used.

In Eqs. 1, 2 and 4, the only unknown is $E_{\mathrm{f}}$; as $l_{\mathrm{f}}, D_{\mathrm{f}}$ and $E_{\mathrm{m}}$ can be measured from the micrographs and the tensile tests of the unmodified epoxy. The value of $E_{\mathrm{f}}$ can be found by linear regression to the experimental data at low nanotube contents, see Fig. 8. This gives the effective Young's modulus of the MWCNTs to be $1100 \mathrm{GPa}$. This value agrees well with the typical Young's modulus of MWCNTs which is quoted to be in the range from 250 to $1200 \mathrm{GPa}$ [50]; however, it does appear somewhat high for catalytic vapour grown nanotubes.

Yeh and co-workers [51, 52] have reported that the modulus of nanotube-modified thermosets does not increase linearly, but that the reinforcement effect reduces at higher volume fractions due to agglomeration. The results shown in Fig. 8 show this effect, as the improvement of the Young's modulus is not linear at higher volume fractions. Yeh et al. [51] modified the shape factor, $\xi$, introducing an exponential factor to account for the effect of agglomeration on the stiffness:

$\xi=2\left[\frac{l_{\mathrm{f}}}{D_{\mathrm{f}}}\right] e^{-a V_{\mathrm{f}}-b}$

in which $a$ and $b$ are constants related to reinforcement agglomeration. However, this expression has three unknowns, $E_{\mathrm{f}}, a$ and $b$. These were ascertained after Yeh et al. [51], by fitting to the linear portion of the data to find $E_{\mathrm{f}}$, then fitting for $a$, and finally $b$. Values of $E_{\mathrm{f}}=1100 \mathrm{GPa}, a=9.15$ and $b=0.12$ were calculated. All the values used in the modified Halpin-Tsai equations are shown in Table 3. The results can be compared with those of Yeh et al. [51], who calculated values of $a=75$ and 55 , and $b=1$ and 0.5 for a phenolic polymer modified with two types of MWCNTs. The lower values of $a$ and $b$ in this study indicate less agglomeration than that observed by Yeh et al.

\section{Fracture energy}

The modelling work in this study also focuses on the toughness of the nanotube-modified materials. The observed toughening mechanisms were nanotube pull-out, plus debonding and plastic void growth. (Note that shear banding is generally not considered for short-fibre composites, and indeed plane-strain compression tests showed none of the strain softening which is generally considered to be a requirement for shear banding to occur [53-55]. Thin sections were cut from the tested plane-strain compression samples. These were placed between crossed polarisers and inspected using TOM, and no evidence of the formation of shear bands was observed).

Fibre pull-out is considered to be the main toughening mechanism in short-fibre-reinforced composites. For MWCNT-modified polymers, Blanco et al. [29] identified (i) nanotube pull-out from the matrix and (ii) sword-insheath pull-out as the toughening mechanisms. For the sword-in-sheath mechanism, the outer shell of the MWCNT fractures in tension and the inner shells pull-out from within it. This leaves the broken outer shell embedded 

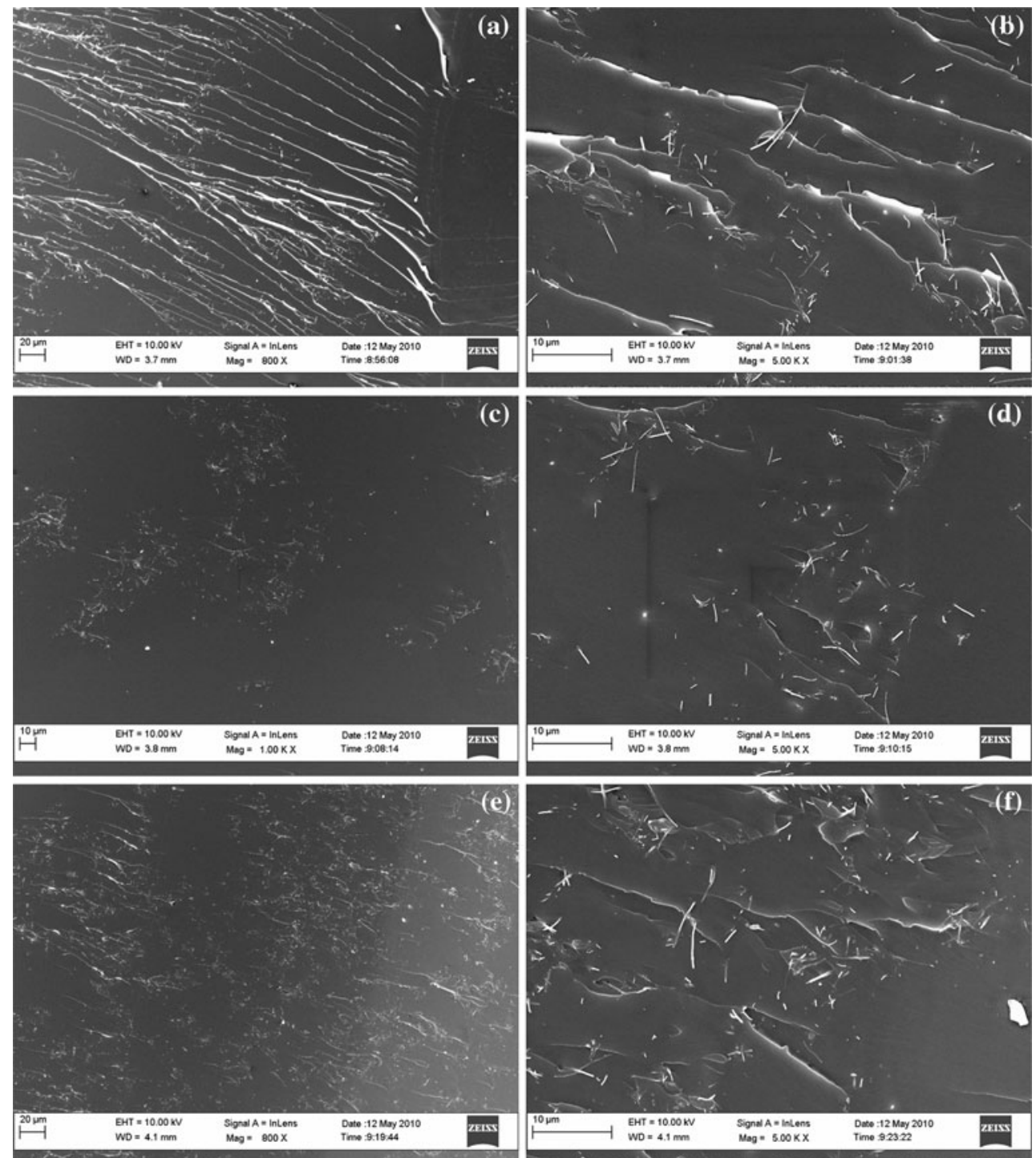

Fig. 5 FEG-SEM images of the fatigue fracture surface of the nanocomposite containing $0.2 \mathrm{wt} \%$ MWCNTs, for the regions of a, b crack initiation, $\mathbf{c}, \mathbf{d}$ propagation, $\mathbf{e}, \mathbf{f}$ threshold. (Crack growth is from right to left)

in the polymer. For void growth to occur, the polymer would need to debond from the shell, so the shell would be observed in the void. This was not observed on the fracture surfaces. Alternatively, the nanotube shell could dilate with the matrix during plastic void growth. However, the high hoop stiffness of the nanotube will prevent void growth occurring. As void growth is observed, the sword-in-sheath pull-out mechanism can be discounted.

Pull-out from the matrix may significantly increase the toughness by the interfacial friction between the fibre and the matrix. Nanotubes possess a high specific surface area (SSA) of typically between 1000 to $1200 \mathrm{~m}^{2} / \mathrm{g}$ [56], which results in a high potential for toughening polymeric composites via this mechanism. The examination of the toughening mechanisms using FEG-SEM of the fracture surfaces shows that nanotube pull-out is indeed present and will contribute to the increase in the toughness of the nanotube/epoxy composites. The energy, $\Delta G_{\text {pull-out }}$, required to pull-out a nanotube can be written as the product of the number of nanotubes involved and the energy required to pull-out each nanotube, by a similar analysis to that of Hull and Clyne [57] for fibres:

$\Delta G_{\text {pull-out }}=\int_{0}^{l_{\mathrm{e}}} \frac{N \mathrm{~d} x}{l_{\mathrm{e}}} \pi r_{\mathrm{f}} x^{2} \tau_{\mathrm{i}}$

where $l_{\mathrm{e}}$ is the effective pulled-out length, $r_{\mathrm{f}}$ is the radius of the fibre (nanotube), $x$ is the length involved in pull-out, $\tau_{\mathrm{i}}$ is the interfacial shear strength and $N$ is the number of nanotubes per unit area: 


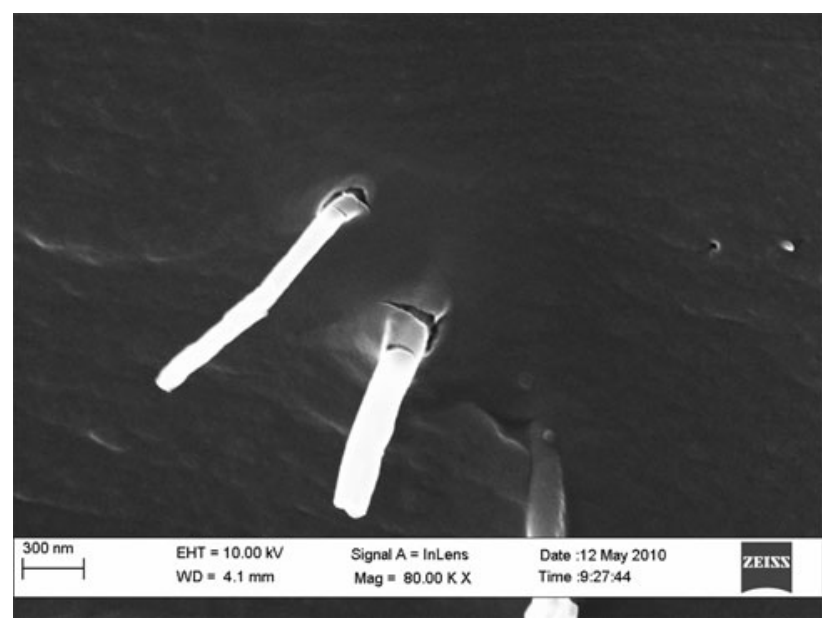

Fig. 6 FEG-SEM images showing voids around nanotubes in the threshold region of the fatigue fracture surface of the nanocomposite containing $0.2 \mathrm{wt} \%$ MWCNTs

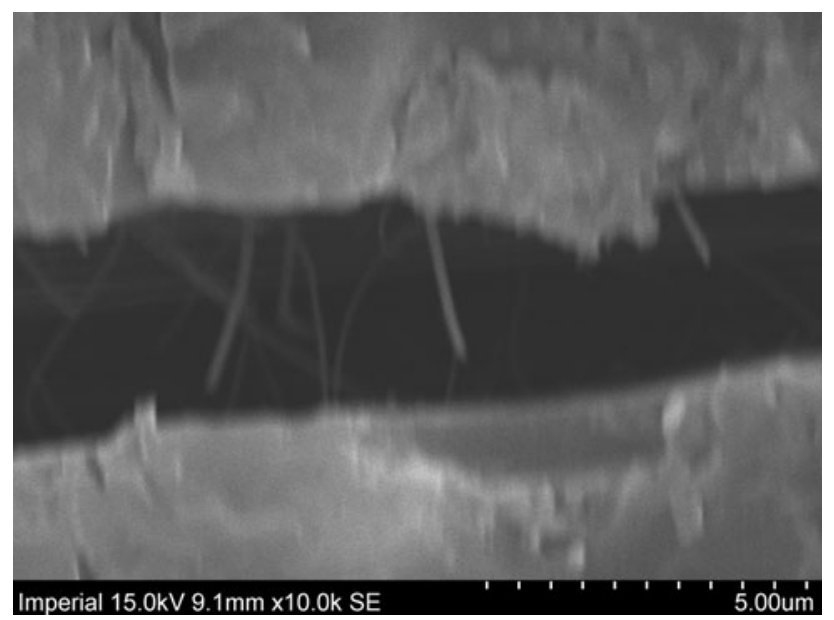

Fig. 7 SEM image showing nanotube bridging and pull-out during the fatigue cracking

$N=\frac{\mathrm{V}_{\mathrm{f}}}{\pi \mathrm{r}_{\mathrm{f}}^{2}}$

where $V_{\mathrm{f}}$ is the volume fraction of nanotubes. Note that the effective pulled-out length will not be equal to the total length of the nanotube, as only a small portion of the nanotube pulls out. The interfacial shear strength between the matrix and the nanotube is unknown for this epoxy matrix. However, Barber et al. [58] measured a value of $47 \mathrm{MPa}$ for polyethylene-butene. Further tests [59] gave a range of values between 15 and $86 \mathrm{MPa}$. Blanco et al. [29] suggested that the value of the interfacial shear strength would lie between 1 and $100 \mathrm{MPa}$, so $47 \mathrm{MPa}$ is a good estimate for use in this study. Substituting Eq. 7 into 6 and integrating gives:

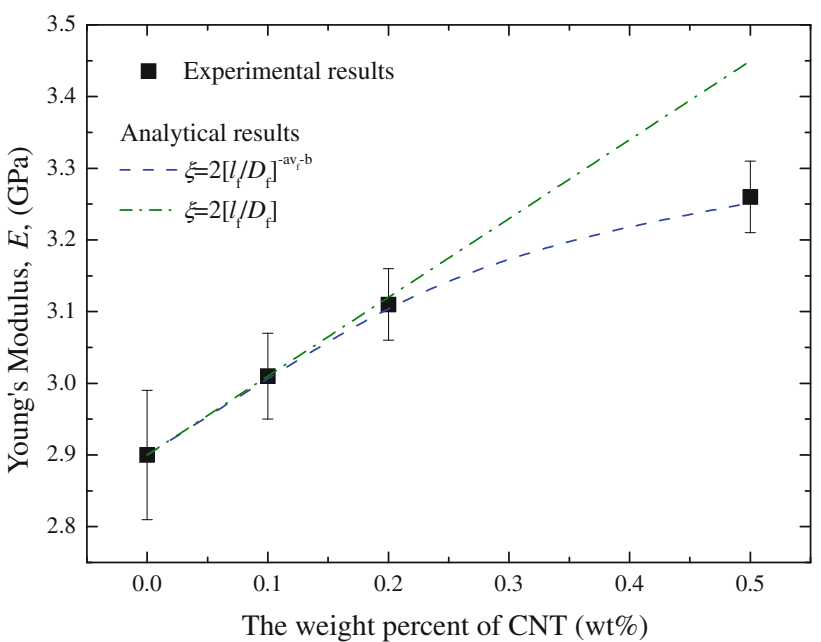

Fig. 8 The experimental Young's modulus fitted by the modified Halpin-Tsai equations

$\Delta \mathrm{G}_{\text {pull-out }}=\frac{V_{\mathrm{fpo}} l_{\mathrm{e}}^{2} \tau_{\mathrm{i}}}{3 \mathrm{r}_{\mathrm{f}}}$

where $V_{\mathrm{fpo}}$ is the volume fraction of nanotubes which are observed to pull-out. As discussed above, not all of the nanotubes were involved in pull-out for the $0.5 \mathrm{wt} \%$ nanotube-modified material. Here, only $62 \%$ of the nanotubes showed pull-out, and the volume fraction, $V_{\mathrm{f}}$, of nanotubes added to the epoxy is corrected accordingly in Eq. 8. The observed bridging can be considered to be part of the pull-out process. The effective CNT pulled-out length used in the model is $7.8 \mu \mathrm{m}$, which is the mean length of the pulled-out nanotubes measured from the fracture surfaces by FEG-SEM.

In addition to the nanotube pull-out mechanism, the plastic void growth of the epoxy matrix initiated by debonding between the nanotubes and the matrix is a major mechanism for improving the toughness. Previous studies $[38,55]$ have calculated the fracture energy contributed by the plastic void growth mechanism, which can be written as:

$\Delta G_{\mathrm{v}}=\left(1-\mu_{\mathrm{m}}^{2} / 3\right)\left(V_{\mathrm{fv}}-V_{\mathrm{fp}}\right) \sigma_{\mathrm{yc}} r_{\mathrm{yu}} K_{\mathrm{vm}}^{2}$

where $V_{\mathrm{fv}}$ and $V_{\mathrm{fp}}$ are the volume fraction of the voids and the volume fraction of nanotubes which showed void growth around them, $\mu_{\mathrm{m}}$ is the material constant allowing for the pressure-dependency of the yield stress [60]. $K_{\mathrm{vm}}$ is the maximum stress concentration for the von Mises stresses around a debonded particle, which is dependent on the volume fraction of the reinforcement [61, 62], and lies between 2.11 and 2.12 for the volume fractions used in this study. $\sigma_{\mathrm{yc}}$ is the compressive yield stress, and $r_{\mathrm{yu}}$ is the plastic zone size at fracture of the unmodified epoxy polymer, which can be calculated using 
Table 3 The parameters used in the modelling studies

\begin{tabular}{lllll}
\hline Name & Symbol & Unit & Value & Source \\
\hline Diameter of nanotube after sonication & $D_{\mathrm{f}}$ & $\mathrm{nm}$ & 120 & Present study \\
Length of nanotube after sonication & $l_{\mathrm{f}}$ & $\mu \mathrm{m}$ & 120 & Present study \\
Density of nanotube & $\rho_{\mathrm{f}}$ & $\mathrm{g} / \mathrm{ml}$ & 1.8 & {$[52]$} \\
Young's modulus of nanotube & $E_{\mathrm{f}}$ & $\mathrm{GPa}$ & 1100 & Calculated \\
Young's modulus of unmodified epoxy & $E_{\mathrm{m}}$ & $\mathrm{GPa}$ & 2.90 & Present study \\
Density of unmodified epoxy & $\rho_{\mathrm{m}}$ & $\mathrm{g} / \mathrm{ml}$ & 1.2 & Present study \\
Fracture energy of unmodified epoxy & $G_{\mathrm{CU}}$ & $\mathrm{J} / \mathrm{m}^{2}$ & 133 & Present study \\
Orientation-related constant & $\alpha$ & - & $1 / 6$ & [49] \\
Agglomeration-related constant & $a$ & - & 9.15 & Calculated \\
Agglomeration-related constant & $b$ & - & 0.12 & Calculated \\
Effective pulled-out length & $l_{\mathrm{e}}$ & $\mu \mathrm{m}$ & 7.82 & Present study \\
Interfacial shear strength & $\tau_{\mathrm{i}}$ & $\mathrm{MPa}$ & 47 & {$[58]$} \\
Poisson's ratio of unmodified epoxy & $v$ & - & 0.35 & {$[55]$} \\
Plane-strain compressive yield stress of unmodified epoxy & $\sigma_{\mathrm{yc}}$ & $\mathrm{MPa}$ & 120 & {$[38]$} \\
True fracture strain of unmodified epoxy & $\gamma_{\mathrm{f}}$ & & 0.75 & {$[55]$} \\
Pressure-dependent yield stress parameter & $\mu_{\mathrm{m}}$ & - & 0.2 & {$[60]$} \\
Maximum von Mises stress concentration & $K_{\mathrm{vm}}$ & - & $2.11-2.12$ & {$[55]$} \\
Uniaxial tensile yield stress & $\sigma_{\mathrm{y}}$ & $\mathrm{MPa}$ & 88 & {$[38]$} \\
Interfacial fracture energy & $G_{\mathrm{i}}$ & $\mathrm{J} / \mathrm{m}^{2}$ & 25 & {$[59]$} \\
\hline & & & & \\
\hline
\end{tabular}

$r_{\mathrm{yu}}=\frac{1}{6 \pi} \frac{E_{\mathrm{m}} G_{\mathrm{CU}}}{\left(1-v^{2}\right) \sigma_{\mathrm{y}}^{2}}$

where $G_{\mathrm{CU}}$ is the fracture energy, $v$ is the Poisson's ratio and $\sigma_{\mathrm{y}}$ is the tensile yield stress of the unmodified material. (Note that this approach effectively predicts the size of the plastic zone in the nanotube-modified polymer. Previous work on nanoparticle-modified epoxies [38] has shown that the predicted diameter of the plastic zone agrees very well with the measured diameter.)

Each void is assumed to be a conical frustum (i.e. a truncated cone) with its smaller diameter equal to the diameter of the nanotube $(120 \mathrm{~nm})$. The larger diameter, i.e. the void size, can be calculated by considering the maximum hoop strain around the nanotubes. If the fracture strain measured from the plane-strain compression tests, i.e. a true strain of 0.75 (see Table 3), is equated with the maximum hoop strain around the void, then a void diameter of $210 \mathrm{~nm}$ is predicted. The values used in the modelling are given in Tables 3 and 4.
Interfacial debonding is essential because it reduces the constraint at the crack-tip, consequently allows the nanotubes to be pulled-out from the matrix, and the epoxy matrix to deform plastically via void growth. The interfacial debonding energy, $\Delta G_{\mathrm{db}}$, is given by [57]:

$\Delta G_{\mathrm{db}}=\frac{V_{\mathrm{fdb}} l_{\mathrm{f}} G_{\mathrm{i}}}{D_{\mathrm{f}}}$

where $V_{\mathrm{fdb}}$ is the volume fraction of nanotubes which debond, and $G_{\mathrm{i}}$ is the interfacial fracture energy between the CNTs and the epoxy. Barber et al. [59] reported $G_{\mathrm{i}}$ values of between 13 and $34 \mathrm{~J} / \mathrm{m}^{2}$ from Zhandarov et al. [63] for glass fibres and vinyl ester (which is quite similar to the epoxy used here). They also reported values for CNTs and polyethylene-butane of a similar magnitude. Hence, a value of $25 \mathrm{~J} / \mathrm{m}^{2}$ will be used here in this study.

From the observations of the fracture surfaces using FEG-SEM, the toughening mechanisms responsible for the increase in the fracture energy of the nanotube-modified epoxy materials are recognised as nanotube pull-out,
Table 4 Measured and predicted values of the fracture energy

\begin{tabular}{lllllllll}
\hline $\begin{array}{l}\text { MWCNT } \\
(\mathrm{wt} \%)\end{array}$ & $\begin{array}{l}V_{\mathrm{fpo}} \\
(\%)\end{array}$ & $\begin{array}{l}V_{\mathrm{fv}}-V_{\mathrm{fp}} \\
(\%)\end{array}$ & $\begin{array}{l}V_{\mathrm{fdb}} \\
(\%)\end{array}$ & $\begin{array}{l}\Delta G_{\text {pull-out }} \\
\left(\mathrm{J} / \mathrm{m}^{2}\right)\end{array}$ & $\begin{array}{l}\Delta G_{\mathrm{v}} \\
\left(\mathrm{J} / \mathrm{m}^{2}\right)\end{array}$ & $\begin{array}{l}\Delta G_{\mathrm{db}} \\
\left(\mathrm{J} / \mathrm{m}^{2}\right)\end{array}$ & $\begin{array}{l}G_{\mathrm{C}}\left(\mathrm{J} / \mathrm{m}^{2}\right) \\
\text { predicted }\end{array}$ & $\begin{array}{l}G_{\mathrm{C}}\left(\mathrm{J} / \mathrm{m}^{2}\right) \\
\text { measured }\end{array}$ \\
\hline 0 & 0 & 0 & 0 & - & - & - & - & 133 \\
0.1 & 0.063 & 0.005 & 0.063 & 10.0 & 0.07 & 15.7 & 159 & 162 \\
0.2 & 0.125 & 0.009 & 0.125 & 20.0 & 0.15 & 31.2 & 184 & 188 \\
0.5 & 0.194 & 0.024 & 0.194 & 31.0 & 0.37 & 48.6 & 213 & 223 \\
\hline
\end{tabular}




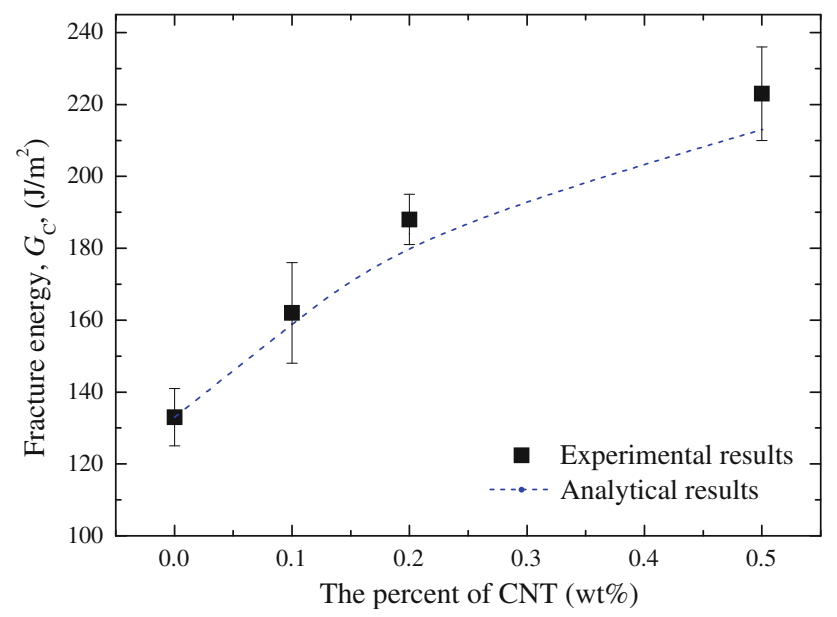

Fig. 9 Fracture energy versus MWCNT content, showing experimental results and theoretical predictions

interfacial debonding and plastic void growth; therefore, the values of the fracture energy of the nanotube-toughened composites can be written as:

$G_{\mathrm{C}}=G_{\mathrm{CU}}+\Delta G_{\text {pull-out }}+\Delta G_{\mathrm{v}}+\Delta G_{\mathrm{db}}$

where $G_{\mathrm{CU}}$ is the measured fracture energy of the unmodified material and has a value for the present epoxy polymer of $133 \mathrm{~J} / \mathrm{m}^{2}$. The predicted values are compared with the experimental results in Table 4 and Fig. 9. Note that the predictions are non-linear with the CNT content as not all of the CNTs show pull-out, or debonding, at the highest content of $0.5 \mathrm{wt} \%$. There is excellent agreement between the measured and the predicted values.

The contributions to the fracture energy from debonding and pull-out of the nanotubes are similar, considering the assumptions made. Void growth of the epoxy matrix after debonding does not contribute significantly to the increase in toughness.

\section{Conclusions}

The modulus, fracture energy and the fatigue performance of an anhydride-cured epoxy modified by MWCNTs have been investigated. The dispersion of the nanotubes was examined by TOM and FEG-SEM, and showed that the nanotubes were agglomerated. Increasing the nanotube content increased the severity of the agglomeration. The addition of nanotubes increased the modulus of the epoxy. The measured fracture energy was also increased, from 133 to $223 \mathrm{~J} / \mathrm{m}^{2}$ with the addition of $0.5 \mathrm{wt} \%$ of nanotubes. The addition of the CNTs also resulted in the increase in the fatigue performance. The threshold strain-energy releaserate, $G_{\text {th }}$, increased from $24 \mathrm{~J} / \mathrm{m}^{2}$ for the unmodified material to $73 \mathrm{~J} / \mathrm{m}^{2}$ for the epoxy with $0.5 \mathrm{wt} \%$ CNTs.
FEG-SEM of the fracture surfaces shows clear evidence of the nanotube debonding and pull-out, with some voids around the nanotubes in both the fracture and fatigue tests.

The modelling study showed that the modified HalpinTsai equation can fit very well with the measured values of the Young's modulus, when the orientation and agglomeration of the nanotubes are considered. The fracture energy of the nanotube-modified epoxies was predicted, by considering the contributions of the toughening mechanisms, of nanotube debonding, nanotube pull-out and plastic void growth of the epoxy matrix. This indicated that debonding and pull-out contribute significantly to the increase in toughness, but the contribution of void growth is not significant. There was excellent agreement between the predictions and the experimental results.

Acknowledgements Some of the equipment used was provided by Dr. Taylor's Royal Society Mercer Junior Award for Innovation.

\section{References}

1. Kinloch AJ, Shaw SJ, Tod DA, Hunston DL (1983) Polymer 24:1341. doi:10.1016/0032-3861(83)90070-8

2. Yee AF, Pearson RA (1986) J Mater Sci 21:2462. doi:10.1007/ BF01114293

3. Bucknall CB, Partridge IK (1983) Polymer 24:639. doi:10.1016/ 0032-3861(83)90120-9

4. Hourston DJ, Lane JM (1992) Polymer 33:1379. doi:10.1016/ 0032-3861(92)90110-I

5. Broutman LJ, Sahu S (1971) Mater Sci Eng 8:98. doi:10.1016/ 0025-5416(71)90087-5

6. Lee J, Yee AF (2000) Polymer 41:8363. doi:10.1016/S00323861(00)00187-7

7. Johnsen BB, Kinloch AJ, Mohammed RD, Taylor AC, Sprenger S (2007) Polymer 48:530

8. Liang YL, Pearson RA (2009) Polymer 50:4895

9. Zilg C, Mulhaupt R, Finter J (1999) Macromol Chem Phys 200:661

10. Becker O, Cheng Y-B, Varley RJ, Simon GP (2003) Macromolecules 36:1616. doi:10.1021/ma0213448

11. Bai JB, Allaoui A (2003) Composites A 34:689. doi:10.1016/ S1359-835X(03)00140-4

12. Shaffer MSP, Kinloch IA (2004) Compos Sci Technol 64:2281. doi:10.1016/j.compscitech.2004.01.018

13. Zhou Y, Pervin F, Jeelani S (2007) J Mater Sci $42: 7544$. doi:10.1007/s10853-007-1618-6

14. Yeh MK, Hsieh TH, Tai NH (2008) Mater Sci Eng A Struct Mater Prop Microstruct Process 483:289. doi:10.1016/ j.msea.2006.09.138

15. Patton RD, Pittman CU Jr, Wang L, Hill JR (1999) Composites A 30:1081. doi:10.1016/S1359-835X(99)00018-4

16. Rafiee MA, Rafiee J, Srivastava I, Wang Z, Song HH, Yu ZZ, Koratkar N (2010) Small 6:179. doi:10.1002/smll.200901480

17. Blackman BRK, Kinloch AJ, Sohn Lee J, Taylor AC, Agarwal R, Schueneman G, Sprenger S (2007) J Mater Sci 42:7049. doi:10.1007/s10853-007-1768-6

18. Manjunatha CM, Taylor AC, Kinloch AJ, Sprenger S (2010) Compos Sci Technol 70:193. doi:10.1016/j.compscitech.2009. 10.012

19. Falvo MR, Clary GJ, Taylor RM, Chi V, Brooks FP, Washburn S, Superfine R (1997) Nature 389:582. doi:10.1038/39282 
20. Xie S, Li W, Pan Z, Chang B, Sun L (2000) J Phys Chem Solids 61:1153. doi:10.1016/S0022-3697(99)00376-5

21. Wong M, Paramsothy M, Xu XJ, Ren Y, Li S, Liao K (2003) Polymer 44:7757. doi:10.1016/j.polymer.2003.10.011

22. Gojny FH, Wichmann MHG, Kopke U, Fiedler B, Schulte K (2004) Compos Sci Technol 64:2363. doi:10.1016/j.compscitech.2004. 04.002

23. Zhang W, Picu RC, Koratkar N (2007) Appl Phys Lett 91:193109. doi:10.1063/1.2809457

24. Zhang W, Picu RC, Koratkar N (2008) Nanotechnology 19:285709. doi:10.1088/0957-4484/19/28/285709

25. Zhang W, Srivastava I, Zhu YF, Picu CR, Koratkar NA (2009) Small 5:1403. doi:10.1002/smll.200801910

26. Rafiee MA, Rafiee J, Wang Z, Song H, Yu Z-Z, Koratkar N (2009) ACS Nano 3:3884. doi:10.1021/nn9010472

27. Marrs B, Andrews R, Pienkowski D (2007) Carbon 45:2098. doi:10.1016/j.carbon.2007.05.013

28. Kim HY, Yasuda HK (1999) J Biomed Mater Res 48:135. doi:10.1002/(sici)1097-4636(1999)48:2<135:aid-jbm7>3.0.co;2-6

29. Blanco J, Garcia EJ, De Villoria RG, Wardle BL (2009) J Compos Mater 43:825

30. Wicks SS, de Villoria RG, Wardle BL (2010) Compos Sci Technol 70:20. doi:10.1016/j.compscitech.2009.09.001

31. Garcia-Cespedes J, Thomasson S, Teo KBK, Kinloch IA, Milne WI, Pascual E, Bertran E (2009) Carbon 47:613. doi:10.1016/ j.carbon.2008.10.045

32. BS-ISO-11357-2 (1999) Plastics-Differential scanning calorimetry (DSC)-Part 2: determination of glass transition temperature. BSI, London

33. ASTM-D638 (2008) Standard test method for tensile properties of plastics. ASTM, West Conshohocken

34. ASTM-D5045 (2007) Standard test method for plane-strain fracture toughness and strain-energy release rate of plastic materials. ASTM, West Conshohocken

35. ASTM-E647 (2005) Standard test method for measurement of fatigue crack growth rates. ASTM, West Conshohocken

36. Giannakopoulos G, Masania K, Taylor AC (2011) J Mater Sci 46:327. doi:10.1007/s10853-010-4816-6

37. Hsieh TH, Kinloch AJ, Taylor AC, Sprenger S (2011) J Appl Polym Sci 119:2135. doi:10.1002/app.32937

38. Hsieh TH, Kinloch AJ, Masania K, Sohn Lee J, Taylor AC, Sprenger S (2010) J Mater Sci 45:1193. doi:10.1007/s10853-0094064-9

39. Kinloch AJ, Osiyemi SO (1993) J Adhes 43:79. doi:10.1080/ 00218469308026589

40. Fernando M, Harjoprayitno WW, Kinloch AJ (1996) Int J Adhes Adhes 16:113. doi:10.1016/0143-7496(96)89799-5
41. Azari S, Papini M, Schroeder JA, Spelt JK (2010) Eng Fract Mech 77:395. doi:10.1016/j.engfracmech.2009.09.011

42. Ashcroft IA, Shenoy V, Critchlow GW, Crocombe AD (2010) J Adhes 86:1203. doi:10.1080/00218464.2010.529383

43. Halpin JC (1969) J Compos Mater 3:732. doi:10.1177/ 002199836900300419

44. Halpin JC, Kardos JL (1976) Polym Eng Sci 16:344. doi:10.1002/ pen.760160512

45. Halpin JC, Pagano NJ (1969) J Compos Mater 3:720. doi: $10.1177 / 002199836900300416$

46. Fisher FT, Bradshaw RD, Brinson LC (2003) Compos Sci Technol 63:1689. doi:10.1016/S0266-3538(03)00069-1

47. Shao LH, Luo RY, Bai SL, Wang J (2009) Compos Struct 87:274. doi:10.1016/j.compstruct.2008.02.011

48. Shady E, Gowayed Y (2010) Compos Sci Technol 70:1476. doi:10.1016/j.compscitech.2010.04.027

49. Cox HL (1952) Br J Appl Phys 3:72. doi:10.1088/0508-3443/3/3/ 302

50. Xie X-L, Mai Y-W, Zhou X-P (2005) Mater Sci Eng R 49:89. doi:10.1016/j.mser.2005.04.002

51. Yeh MK, Tai NH, Liu JH (2006) Carbon 44:1. doi:10.1016/ j.carbon.2005.07.005

52. Tai N-H, Yeh M-K, Peng T-H (2008) Compos B Eng 39:926. doi:10.1016/j.compositesb.2008.01.003

53. Bowden PB (1970) Philos Mag 22:455. doi:10.1080/ 14786437008225836

54. Bowden PB (1973) In: Haward RN (ed) The physics of glassy polymers, 1st edn. Applied Science Publishers, London, p 279

55. Hsieh TH, Kinloch AJ, Masania K, Taylor AC, Sprenger S (2010) Polymer 51:6284. doi:10.1016/j.polymer.2010.10.048

56. Peigney A, Laurent C, Flahaut E, Bacsa RR, Rousset A (2001) Carbon 39:507. doi:10.1016/S0008-6223(00)00155-X

57. Hull D, Clyne TW (1996) An introduction to composite materials. Cambridge solid state science series, 2nd edn. Cambridge University Press, Cambridge

58. Barber AH, Cohen SR, Wagner HD (2003) Appl Phys Lett 82:4140. doi:10.1063/1.1579568

59. Barber AH, Cohen SR, Kenig S, Wagner HD (2004) Compos Sci Technol 64:2283. doi:10.1016/j.compscitech.2004.01.023

60. Sultan JN, McGarry FJ (1973) Polym Eng Sci 13:29. doi:10.1002/pen.760130105

61. Guild FJ, Young RJ (1989) J Mater Sci 24:298. doi:10.1007/ BF00660971

62. Guild FJ, Young RJ (1989) J Mater Sci 24:2454. doi:10.1007/ BF01174511

63. Zhandarov S, Pisanova E, Mader E, Nairn JA (2001) J Adhes Sci Technol 15:205 